\title{
Social Participation after Stroke: One-Year Follow-Up of Stroke Survivors in Nigeria
}

\author{
Grace O. Vincent-Onabajo \\ Department of Medical Rehabilitation (Physiotherapy), College of Medical Sciences, University of Maiduguri, \\ Maiduguri, Borno State 600001, Nigeria \\ Correspondence should be addressed to Grace O. Vincent-Onabajo; teetoe262003@yahoo.com
}

Received 12 August 2013; Accepted 4 September 2013

Academic Editors: E. Berge, C. J. McKevitt, H. McNaughton, J. Mocco, and M. Paciaroni

Copyright (C) 2013 Grace O. Vincent-Onabajo. This is an open access article distributed under the Creative Commons Attribution License, which permits unrestricted use, distribution, and reproduction in any medium, provided the original work is properly cited.

\begin{abstract}
Background. Stroke may negatively affect social participation in survivors. Aims. This study assessed the pattern of social participation in a sample of Nigerian stroke survivors across the first 12 months after stroke. Methods. Stroke survivors were consecutively recruited while on admission at a tertiary health institution. The London handicap scale was used to assess social participation at 1, 3, 6, 9, and 12 months at the homes of the stroke survivors. Overall and domain-specific patterns of social participation were examined independently and also in relation to initial stroke severity. Results. Overall social participation significantly improved over 12 months $(P<0.0001)$, while significant improvements were observed only in the mobility, physical independence, and work and leisure domains at $P$ equals $0.04,0.04$, and 0.05 , respectively. In spite of the improvement in the work and leisure domain, the domain recorded the lowest level of participation. Social participation also differed by initial stroke severity with severe stroke survivors having the lowest level of participation across 12 months after stroke. Conclusions. The poor outcome in the work and leisure domain of social participation and in individuals with initial severe stroke has implications for planning and provision of appropriate long-term stroke rehabilitation.
\end{abstract}

\section{Introduction}

Social participation is a component of human functioning that reflects the complexity of a person's roles beyond the performance of activities of daily life [1]. Defined as an individual's involvement in life situations [2], social participation is increasingly being recognized as an important aspect of life. Furthermore, appropriateness in the dimensions of social participation such as community life, leisure, educational and occupational activities, social integration, and economic selfsufficiency have been linked with improved well-being and quality of life in general populations $[3,4]$ as well as in those with chronic diseases such as stroke $[5,6]$.

Stroke is a life changing disease that often entails lifelong consequences including social ones [7]. With increasing rates of survival after stroke, there is a growing need for evidencebased interventions that will enhance social functioning and participation in survivors. However, devising, planning, and provision of appropriate interventions may require adequate data on patterns of social participation after stroke.
Existing studies from Western and Asian countries are varied with reports on improvement $[8,9]$, deterioration $[10,11]$, and stability $[12,13]$ in social participation over time after stroke. Aside the differences in study methodology such as length of followup, selection of participants, and data collection tools, environmental factors appear to contribute to differences in patterns of social participation across studies since the construct is culture sensitive [14]. Findings from a study conducted in countries in the European Union showed regional differences in the patterns of social participation in senior citizens signifying the substantial influence of different national and cultural settings [15]. The influence of diverse cultural and socioeconomic backgrounds and health care systems on post stroke social participation has also been suggested [8]. Country-specific data would, therefore, be required to understand the longitudinal trends of social participation after stroke and to devise interventions suited to societal particularities.

Longitudinal studies on after stroke social participation are rare in Nigeria. The only available published data 
emanated from a study conducted across the first 6 months after stroke which reported improvements in social participation over the study period [16]. However, resettling and reintegration of stroke survivors into the community, which is particularly relevant for social participation, often span longer than the first 6 months after stroke. The aims of this study were, therefore, to examine the patterns of overall and domain-specific social participation in stroke survivors in Nigeria over the first 12 months and also to identify differences in social participation by severity of stroke at onset.

\section{Materials and Methods}

\subsection{Study Design. A 12-month longitudinal study.}

2.2. Study Setting. Stroke survivors were recruited from the medical wards of a university teaching hospital in Nigeria. All stroke survivors were recipients of medical and nursing care and physiotherapy; all of which constitute routine stroke management in tertiary-care hospitals in the country. Following discharge from the hospital, rehabilitation for stroke survivors takes place through out-patient physiotherapy as there are no in-patient rehabilitation centers in Nigeria. After hospital discharge, follow-up assessments were carried out at the homes of the stroke survivors or of their relatives.

2.3. Participants. Eighty-three first-incidence stroke survivors were consecutively recruited within the first four weeks of stroke onset. Ability to communicate in English or Hausa language and provision of informed consent by the participants or a family member were the eligibility criteria. Stroke survivors were stratified into groups according to level of stroke severity at baseline using the stroke levity scale (SLS) [17].

2.4. Measures. Stroke levity scale [17]: The SLS was used at baseline to assess stroke severity. The scale examines maximum power in the dexterous hand and weaker lower limb, mobility, and aphasia, if present. The score for the lower limb is determined by the maximum motor power across the hip or ankle joint by assessing hip flexion and ankle dorsiflexion, while the power in the distal arm is tested by asking the stroke survivor to extend the wrist whilst making a fist. Aphasia grading is coded as present or absent depending on the ability of the stroke survivor both to name an object and to comprehend and carry out instructions during assessment. Mobility is graded from bed bound to walking unaided on a scale of 1-5. The total obtainable score on the SLS is 15 , and severe stroke is represented by a score of 0 to 5 ; scores ranging from 6 to 10 depict moderate severity, while $11-15$ is mild severity. Valid and reliable, the SLS has a high criterion validity of $r=-0.79$ with the National Institute of Health Stroke Scale (NIHSS) as the criterion measure and a good internal consistency represented by Cronbach's alpha of 0.75 [17].

The London handicap scale (LHS) [18]: The LHS was used to assess social participation of stroke survivors.
The scale consists of 6 domains, namely, mobility, orientation, occupation (work and leisure), physical independence, social integration, and economic self-sufficiency, and each domain is scored on a six-point scale of 0 to 5 . The unweighted simple summation scoring system was used to calculate the total social participation score in this study with total obtainable score ranging from 0 to 30 [19]. The scores were converted to a scale of 100 with a range of 0 (maximum restriction) to 100 (no restriction). For purposes of analyzing domain patterns, the score for each domain which ranged from 0 to 5 was utilized, with 0 and 5 indicating maximum participation restriction and no restriction, respectively. Although the LHS was developed based on the conceptual framework of the international classification of impairment, disability and handicap $(\mathrm{ICIDH})$, the scale is an appropriate measure of participation and its dimensions are relevant and represented in the international classification of functioning, disability and health (ICF) - the more recent framework in which the participation construct replaces the ICIDH's handicap construct [19]. The LHS had previously been validated for assessing participation in Nigerian stroke survivors [20].

2.5. Procedure. Approval for the study was obtained from the appropriate institution ethics committees. At recruitment which was within the first four weeks after stroke, informed consent and participants' demographic and clinical data, namely age, gender, stroke subtype, stroke severity, and side of hemiplegia or hemiparesis were obtained. Information on post-hospital-discharge residence and telephone numbers (where available) were also obtained for purposes of followup. Assessments of participation were conducted at the 1st, 3rd, 6th, 9th, and 12th months after baseline assessment at the places of abode of the stroke survivors.

2.6. Statistical Analyses. Descriptive statistics were used to summarize demographic and clinical data. Age was presented as mean and standard deviation, while categorical variables such as gender, side, severity, and subtype of stroke were presented as frequencies and percentages; severity of stroke was stratified into mild, moderate and severe.

Friedman's ANOVA (a nonparametric equivalent of repeated measure ANOVA) was used to study the pattern of overall social participation at the 1st, 3rd, 6th, 9th, and 12th months after onset of stroke. Post-hoc analyses were computed using the Wilcoxon Signed-Rank test for significant difference in overall social participation between pairs of time points, and the Holm's sequential Bonferroni adjustment for multiple tests of significance [21] was utilized. KruskalWallis analysis was used to compare median scores of social participation among the three strata of stroke severity across 5 time points (1, 3, 6, 9, and 12 months). Mean scores for each of the domains of social participation as assessed by the LHS were computed for 1 and 12 months, while difference in each domain between the two time points was analyzed using the Wilcoxon Signed-Rank test. Level of statistical significance was set a priori at $P=0.05$. 
TABLE 1: Demographic and clinical characteristics of study participants.

\begin{tabular}{|c|c|c|c|c|c|}
\hline \multirow[b]{2}{*}{ Variable } & \multirow{2}{*}{$\begin{array}{c}\text { Completers (55) } \\
n(\%)\end{array}$} & \multicolumn{2}{|c|}{ Noncompleters $(n=28)$} & \multirow[b]{2}{*}{ Test $^{*}$} & \multirow[b]{2}{*}{$P$ value } \\
\hline & & $\begin{array}{c}\text { Attrition }(n=21) \\
n(\%)\end{array}$ & $\begin{array}{c}\text { Dead }(n=7) \\
n(\%)\end{array}$ & & \\
\hline \multicolumn{6}{|l|}{ Gender } \\
\hline Male & $33(60)$ & $16(76.2)$ & $5(71.4)$ & \multirow{2}{*}{1.81} & \multirow{2}{*}{0.42} \\
\hline Female & $22(40)$ & $5(23.8)$ & $2(28.6)$ & & \\
\hline \multicolumn{6}{|l|}{ Stroke subtype } \\
\hline Ischemic & $39(70.9)$ & $16(76.2)$ & $4(57.1)$ & \multirow{3}{*}{5.88} & \multirow{3}{*}{0.16} \\
\hline Hemorrhagic & $14(25.5)$ & $2(9.5)$ & $2(28.6)$ & & \\
\hline Unknown & $2(3.6)$ & $3(14.3)$ & $1(14.3)$ & & \\
\hline \multicolumn{6}{|l|}{ Side of hemiplegia } \\
\hline Left & $33(60)$ & $8(38.1)$ & $2(28.6)$ & \multirow{2}{*}{4.46} & \multirow{2}{*}{0.10} \\
\hline Right & $22(40)$ & $13(61.9)$ & $5(71.4)$ & & \\
\hline \multicolumn{6}{|c|}{ Stroke severity (stroke levity scale) } \\
\hline Severe & $26(47.3)$ & $11(52.4)$ & $4(57.1)$ & \multirow{3}{*}{2.31} & \multirow{3}{*}{0.69} \\
\hline Moderate & $20(36.4)$ & $9(42.9)$ & $3(42.9)$ & & \\
\hline Mild & $9(16.4)$ & $1(4.8)$ & $0(0)$ & & \\
\hline \multicolumn{6}{|l|}{ Age (years) } \\
\hline Mean \pm SD & $58.0 \pm 12.78$ & $54.7 \pm 13.7$ & $63.1 \pm 22.3$ & \multirow[t]{2}{*}{1.03} & \multirow{2}{*}{0.36} \\
\hline Range & $31-85$ & $28-75$ & $35-95$ & & \\
\hline
\end{tabular}

${ }^{*}$ Test

One-way ANOVA for Age.

Fisher's Exact Test for other variables.

\section{Results}

3.1. Demographic and Clinical Characteristics of Stroke Survivors. Eighty-three stroke survivors were recruited for this study out of which 55 (66.3\%) completed the 12-month followup. Dropout was due to death (7), voluntary withdrawal (2), and loss to followup (19). Mean age of those who completed the study was $58.0 \pm 12.78$ years, and majority were males (60\%), suffered ischemic stroke (70.9\%), and presented with left hemiplegia (60\%). There was however no significant difference in demographic and clinical characteristics between completers and noncompleters of the study (Table 1).

3.2. Pattern of Overall Social Participation across 12 Months. Significant improvement in social participation was observed over the 12 months of followup at $P<0.0001$. Result of the Wilcoxon Signed-Rank test for comparisons of median social participation scores between pairs of months showed existence of statistically significant differences all through except between the 9th month (median score $=70$ ) and 12th month (median score $=71$ ) at $P=0.12$ (Figure 1 ). Differences in median social participation (LHS) scores between 1 and 3 months (57 and 60), 3 and 6 months (60 and 63), and 6 and 9 months (63 and 70) were significant with $P$ equals $0.00,0.01$, and 0.01 , respectively (Figure 1 ).

3.3. Social Participation by Initial Stroke Severity. Although social participation improved over 12 months irrespective of initial stroke severity, pattern differed among the 3 severity

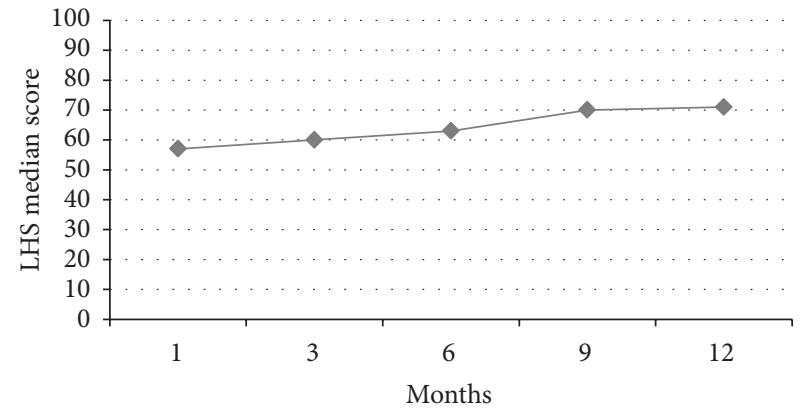

Figure 1: Pattern of overall participation across 12 months.

strata (Figure 2). Over 12 months, survivors with mild stroke had significantly higher social participation scores (median score at 1 month $=65$ and median score at 12 months $=$ 83 ) than those with moderate stroke (median score at 1 month $=49.6$ and median score at 12 months $=72$ ), while survivors with severe stroke had the lowest participation scores (median score at 1 month $=30$ and median score at 12 months $=60)$ (Figure 2$)$. Alpha $(P$ value $)$ for differences in social participation among the 3 strata of stroke severity was 0.00 at 3,6, and 12 months, while it was 0.03 and 0.01 at 1 and 9 months, respectively.

3.4. Patterns of and Changes in Domain-Specific Social Participation across 12 Months. Patterns of the domains of social participation were examined at 1 and 12 months with results 


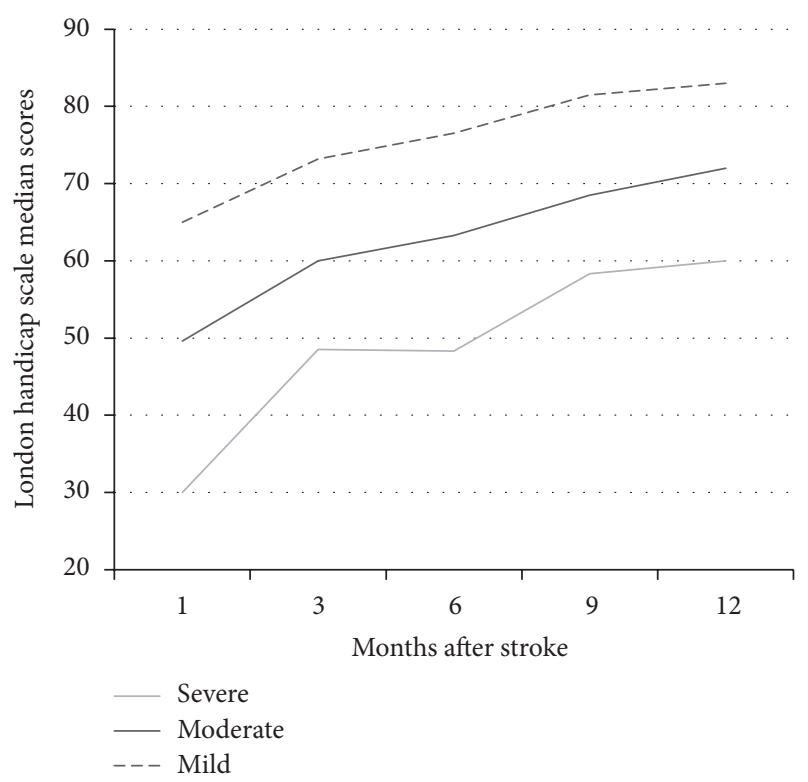

FIGURE 2: Differences in patterns of participation among stroke survivors with mild, moderate, and severe stroke at onset.

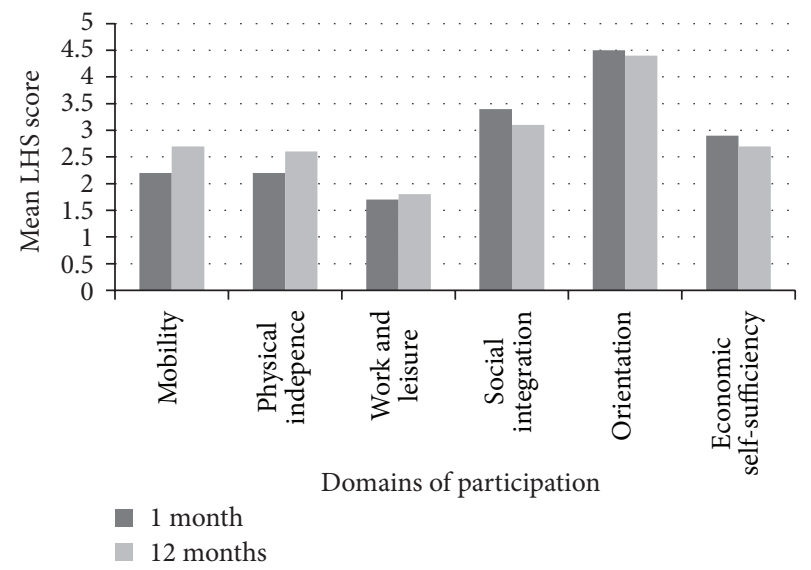

Figure 3: Changes in domains of participation between 1 and 12 months after stroke.

showing the highest mean scores in the orientation domain (1 month $=4.46 \pm 0.97$ and 12 months $=4.36 \pm 1.05)$ and lowest scores in the work and leisure domain $(1$ month $=1.77 \pm 1.59$ and 12 months $=1.82 \pm 1.56$ ) (Figure 3 ). By comparing scores obtained at 1 and 12 months, changes in the mobility, physical independence, and work and leisure domains were positive and statistically significant at $P$ equals $0.04,0.04$, and 0.05 , respectively.

\section{Discussion}

Social participation is positively associated with important stroke outcomes such as motor function [16], quality of life [6], and subjective well-being and life satisfaction [5]. Enhancement and optimization of social participation is therefore an essential component of successful stroke care.
This study explored the longitudinal patterns of social participation among Nigerian stroke survivors in the first 12 months after stroke. Progressive and statistically significant linear improvement was observed up to the first 9 months after stroke onset and continued till the 12th month. Improvements in participation over the first 12 months after stroke have been previously reported. In a study of stroke survivors in Ireland, Horgan et al. [9] reported significant improvement in participation within the first year of stroke especially between 6 and 12 months. Another study in Australia reported less participation restriction at 12 months after stroke compared with 3 months [8]. These findings on improvement in social participation over time imply that recovery after stroke is not just limited to body functions and functional abilities. For instance, reduction in level of disability during the first year of stroke has been found to result in improved participation [13].

Changes in the individual domains of social participation between the 1st and 12th months were explored with significant improvements observed in the mobility, physical independence, and work and leisure domains. In a previous study, these 3 domains described as being closely linked to body function, appeared to exhibit common patterns as they were uniformly influenced by the stroke survivors' functional activity and emotional status unlike other domains of social participation [12]. However, in that study, mobility and physical independence were the most severely restricted domains [12] as in some other studies [8, 18]. Conversely, another study reported improvement in the mobility domain of social participation between 3 and 12 months after stroke [13], a finding similar to what was observed in this present study. Mobility after stroke is an important source of concern to stroke survivors. Identified as a major impetus for their continued involvement in rehabilitation [22], restoration of mobility is often an important goal of stroke rehabilitation.

Similar to findings from a previous study [8], social participation was highest in the orientation domain in this study. The orientation domain as assessed with the London handicap scale involves the ability to understand the world in terms of hearing, seeing, speaking, thinking, and possessing good memory [18]. Lo et al. [13] however reported the most significant deterioration in the orientation domain. The average age of stroke survivors in their study was 70 years and the comparatively younger age of stroke survivors in this present study could perhaps explain the disparity in findings since old age has been associated with poor orientation [13]. Social participation was however markedly restricted in the work and leisure domain across 12 months in this study in line with previous reports $[8,18,23]$. This is in spite of the significant improvement in the domain over time. This somewhat paradoxical finding is suggestive of the potential for improvement in the domain which was perhaps not fully exploited to enable high levels of work and leisure participation in the stroke survivors, and this has implications for the provision of vocational and leisure rehabilitation services when required after stroke. Findings from the only study on return to work in Nigerian stroke survivors have shown that the first year after stroke is characterized by significantly lower chance of returning to work possibly as a result 
of the non-availability of specialized rehabilitation centers in Nigeria [24]. The existing status of stroke rehabilitation in Nigeria will require a thorough overhaul to be able to effectively address a multidimensional and long-term stroke outcome like social participation. For instance, the absence of standard multi- and interdisciplinary stroke care teams and the characteristic unidisciplinary (physiotherapy) stroke rehabilitation in the country traceable to the pronounced scarcity of other rehabilitation professionals such as occupational therapists and speech therapists must be addressed as well as issues of poor and inadequate rehabilitation facilities and dearth of well-funded and robust therapeutic trials on culturally sensitive and suitable rehabilitation techniques.

Based on initial severity of stroke, social participation of the stroke survivors differed, with those who had mild stroke recording a higher degree of participation than those with moderate and severe stroke. This finding suggests that the strata of stroke severity within the first month after stroke were reflected in the patterns of social participation across the succeeding 12 months. According to Kwakkel et al. [25], severity of stroke within 1 month after onset plays a crucial role in predicting stroke outcomes. Furthermore, initial stroke severity has been associated with after stroke functional activity [25] and health-related quality of life [26, 27] with predictive ability valid for as long as 2 years after the stroke event in some cases. These findings are indicative of the far-reaching consequences of initial stroke severity and imply that individuals with severe stroke may require extra rehabilitation strategies because of their higher likelihood for long-term negative outcomes such as marked participation restriction as observed in this study.

This study has several limitations. Its hospital-based recruitment design could have resulted in selection bias which reduces the generalizability of findings. The high rate of drop-out and subsequent small size of the sample of stroke survivors that completed the study also constitute a considerable limitation. Nonetheless, the study represents the first effort at exploring the patterns of Nigerian stroke survivors' social participation in the first 12 months after stroke onset which perhaps contributes insight to some of their rehabilitation needs.

\section{Conclusions}

The outcome of this study suggests that there is a marked potential for the improvement of social participation across the first 12 months of stroke especially in the mobility, physical independence, and work and leisure domains. However, there is need to optimize this potential through appropriate interventions and programmes. For instance, the significant improvement observed in the work and leisure dimension of social participation over 12 months did not result in an optimal outcome rather the domain recorded the lowest level of participation at the end of the study. Also, individuals with severe stroke at onset were more disadvantaged in overall social participation over 12 months than those with mild and moderate stroke and would likely require additional support and interventions to enhance their social participation.

\section{Conflict of Interests}

The author declares that there is no conflict of interests regarding the publication of this paper.

\section{References}

[1] M. Levasseur, J. Desrosiers, and D. S.-C. Tribble, "Do quality of life, participation and environment of older adults differ according to level of activity?" Health and Quality of Life Outcomes, vol. 6, article 30, 2008.

[2] World Health Organization, International Classification of Functioning, Disability and Health-ICF, World Health Organization, Geneva, Switzerland, 2001.

[3] K. M. Bennett, "Social engagement as a longitudinal predictor of objective and subjective health," European Journal of Ageing, vol. 2, no. 1, pp. 48-55, 2005.

[4] J. Field, "Well-being and happiness," Inquiring into the Future of Lifelong Learning (IFLL) Thematic Paper 4, National Institute of Adult Continuing Education, 2009, http://www.niace.org.uk/ lifelonglearninginquiry/docs/IFLL-wellbeing.pdf.

[5] M. Vestling, B. Tufvesson, and S. Iwarsson, "Indicators for return to work after stroke and the importance of work for subjective well-being and life satisfaction," Journal of Rehabilitation Medicine, vol. 35, no. 3, pp. 127-131, 2003.

[6] T. Kwok, J.-H. Pan, R. Lo, and X. Song, "The influence of participation on health-related quality of life in stroke patients," Disability and Rehabilitation, vol. 33, no. 21-22, pp. 1990-1996, 2011.

[7] P. Vanhook, "The domains of stroke recovery: a synopsis of the literature," The Journal of Neuroscience Nursing, vol. 41, no. 1, pp. 6-17, 2009.

[8] J. W. Sturm, H. M. Dewey, G. A. Donnan, R. A. L. Macdonell, J. J. McNeil, and A. G. Thrift, "Handicap after stroke: how does it relate to disability, perception of recovery, and stroke subtype? The North East Melbourne Stroke Incidence Study (NEMESIS)," Stroke, vol. 33, no. 3, pp. 762-768, 2002.

[9] N. F. Horgan, M. O’Regan, C. J. Cunningham, and M. Finn, "Recovery after stroke: a 1-year profile," Disability and Rehabilitation, vol. 31, no. 10, pp. 831-839, 2009.

[10] R. Mayer and D. Reid, "Changes in autonomy and participation in seniors after stroke," Activities, Adaptation and Aging, vol. 28, no. 3, pp. 49-70, 2004.

[11] M. D. Patel, K. Tilling, E. Lawrence, A. G. Rudd, C. D. A. Wolfe, and C. McKevitt, "Relationships between long-term stroke disability, handicap and health-related quality of life," Age and Ageing, vol. 35, no. 3, pp. 273-279, 2006.

[12] S. D’Alisa, S. Baudo, A. Mauro, and G. Miscio, "How does stroke restrict participation in long-term post-stroke survivors?" Acta Neurologica Scandinavica, vol. 112, no. 3, pp. 157-162, 2005.

[13] R. S. K. Lo, J. O. Y. Cheng, E. M. C. Wong et al., "Handicap and its determinants of change in stroke survivors: one-year followup study," Stroke, vol. 39, no. 1, pp. 148-153, 2008.

[14] J. Desrosiers, D. Bourbonnais, L. Noreau, A. Rochette, G. Bravo, and A. Bourget, "Participation after stroke compared to normal aging," Journal of Rehabilitation Medicine, vol. 37, no. 6, pp. 353357, 2005.

[15] T. Leone and P. Hessel, "The effect of "social participation" on the subjective and objective health status of the over 50: evidence from share," March 2013, http://www2.lse.ac.uk/ LSEHealthAndSocialCare/pdf/Leone_Hessel_PDF.pdf. 
[16] T. K. Hamzat and G. O. Peters, "Motor function and participation among Nigerian stroke survivors: 6-month follow-up study," Neurorehabilitation, vol. 25, no. 2, pp. 137-142, 2009.

[17] M. O. Owolabi and T. Platz, "Proposing the stroke levity scale: a valid, reliable, simple, and time-saving measure of stroke severity," European Journal of Neurology, vol. 15, no. 6, pp. 627633, 2008.

[18] R. H. Harwood, P. Gompertz, and S. Ebrahim, "Handicap one year after a stroke: validity of a new scale," Journal of Neurology, Neurosurgery and Psychiatry, vol. 57, no. 7, pp. 825-829, 1994.

[19] C. Jenkinson, J. Mant, J. Carter, D. Wade, and S. Winner, "The London handicap scale: a re-evaluation of its validity using standard scoring and simple summation," Journal of Neurology, Neurosurgery and Psychiatry, vol. 68, no. 3, pp. 365-367, 2000.

[20] T.-H. K. Hamzat and G. O. Peters, "The London handicap scale: validation of a yoruba (Nigerian) version among stroke survivors," African Journal of Neurological Sciences, vol. 28, no. 1, pp. 65-71, 2009.

[21] S. Holm, "A simple sequentially rejective multiple test procedure," Scandinavian Journal of Statistics, vol. 6, pp. 65-70, 1979.

[22] S. E. Lord and L. Rochester, "Measurement of community ambulation after stroke: current status and future developments," Stroke, vol. 36, no. 7, pp. 1457-1461, 2005.

[23] J. Desrosiers, F. Malouin, D. Bourbonnais, C. L. Richards, A. Rochette, and G. Bravo, "Arm and leg impairments and disabilities after stroke rehabilitation: relation to handicap," Clinical Rehabilitation, vol. 17, no. 6, pp. 666-673, 2003.

[24] G. O. Peters, S. G. Buni, A. Y. Oyeyemi, and T. K. Hamzat, "Determinants of return to work among Nigerian stroke survivors," Disability and Rehabilitation, vol. 35, no. 6, pp. 455-459, 2012.

[25] G. Kwakkel, B. J. Kollen, J. van der Grond, and A. J. H. Prevo, "Probability of regaining dexterity in the flaccid upper limb: impact of severity of paresis and time since onset in acute stroke," Stroke, vol. 34, no. 9, pp. 2181-2186, 2003.

[26] J. W. Sturm, G. A. Donnan, H. M. Dewey et al., "Quality of life after stroke: the North East Melbourne Stroke Incidence Study (NEMESIS)," Stroke, vol. 35, no. 10, pp. 2340-2345, 2004.

[27] G. Gosman-Hedström, L. Claesson, and C. Blomstrand, "Consequences of severity at stroke onset for health-related quality of life (HRQL) and informal care: a 1-year follow-up in elderly stroke survivors," Archives of Gerontology and Geriatrics, vol. 47, no. 1, pp. 79-91, 2008. 


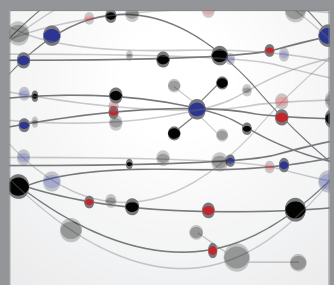

The Scientific World Journal
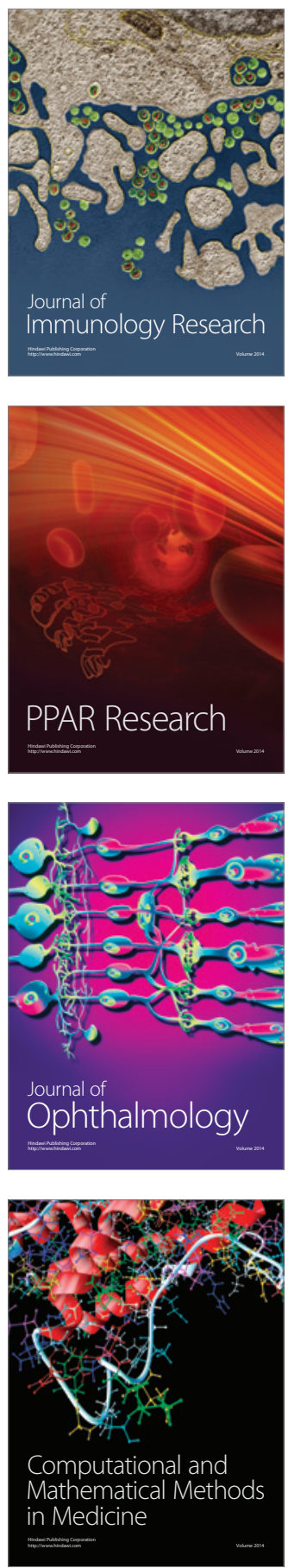

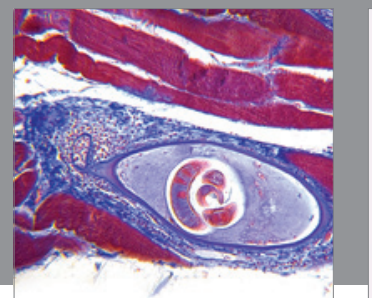

Gastroenterology

Research and Practice
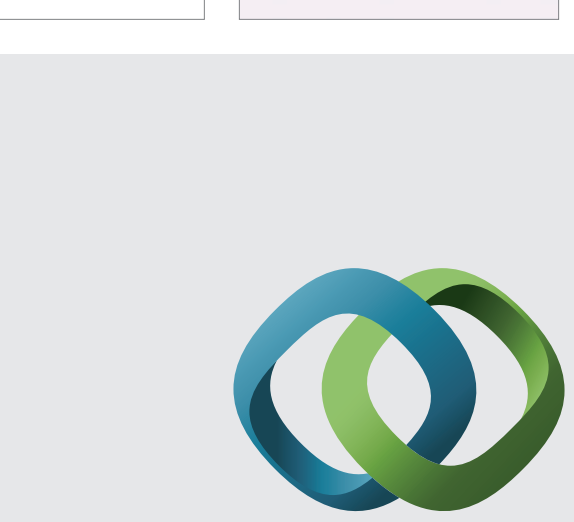

\section{Hindawi}

Submit your manuscripts at

http://www.hindawi.com
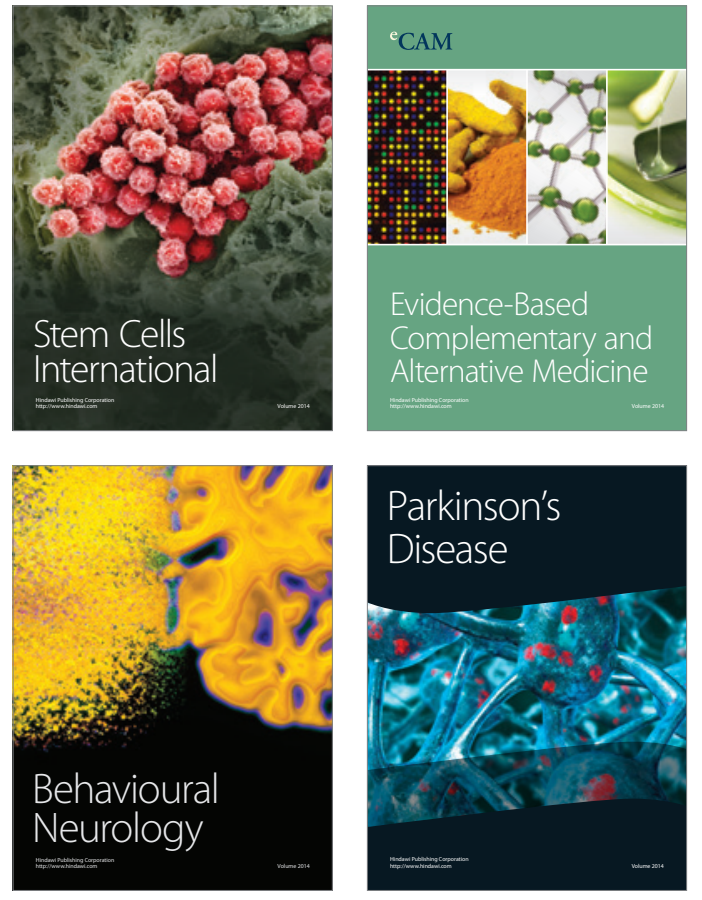
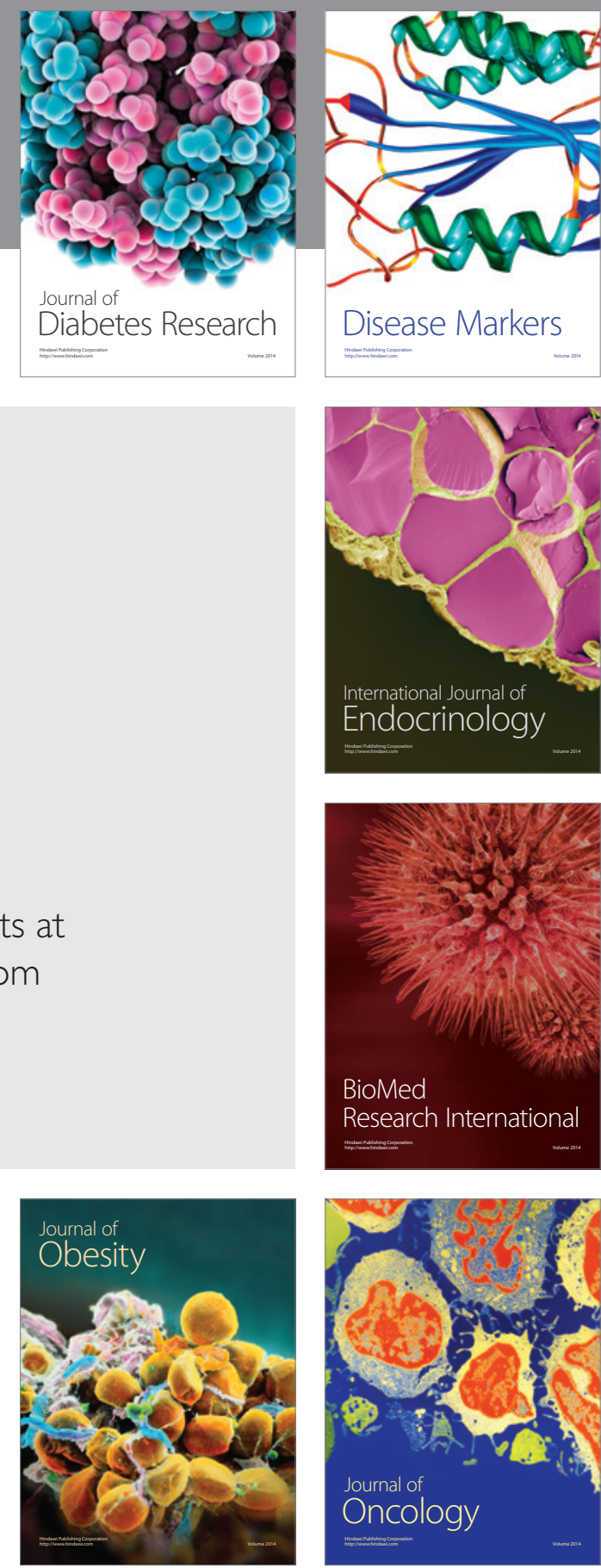

Disease Markers
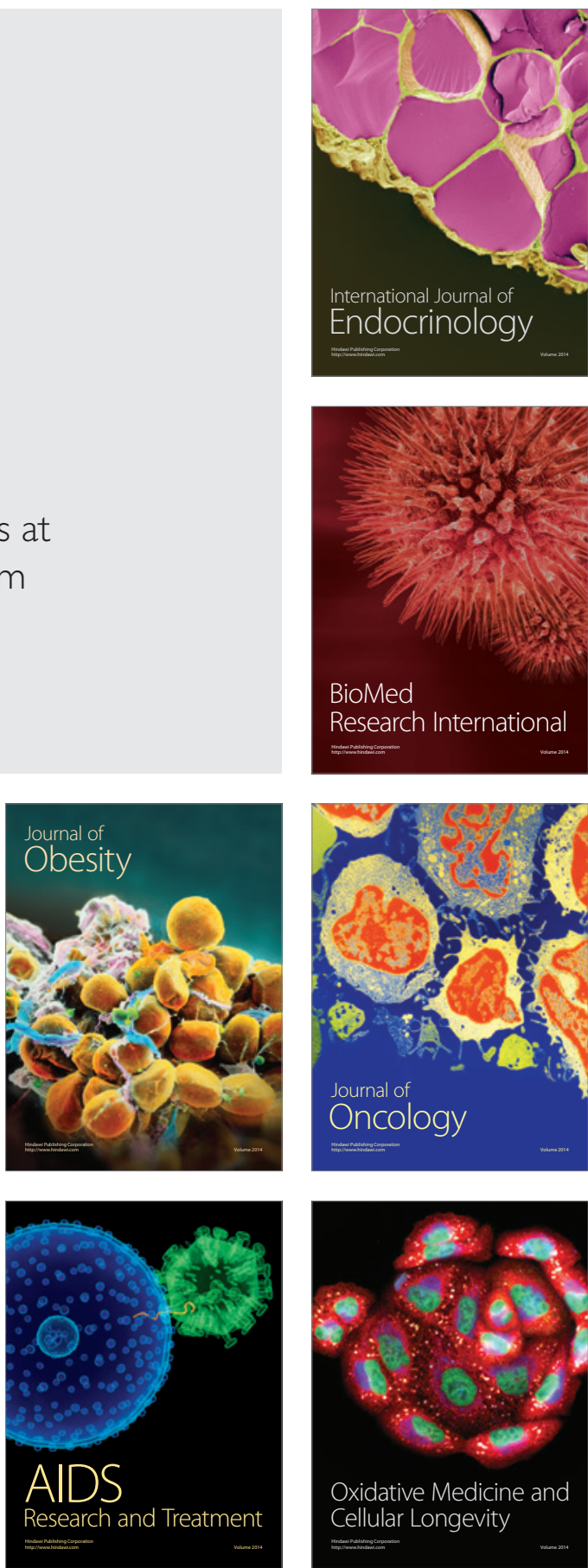